\title{
The Evaluation of Occupational Health and Safety (OHS) Implementation in Vocational High School Workshop, Surakarta
}

\author{
Basori \\ Computer and Informatics Engineering Education Department \\ Universitas Sebelas Maret \\ Surakarta, Indonesia \\ basori@staff.uns.ac.id
}

\begin{abstract}
The high number of work accidents due to human error or other factors is one the needs to be considered in the framework of both industry and educational institutions. This study is intended to determine the effectiveness of the level of implementation of Occupational Health and Safety (OHS) regulations in vocational schools in Surakarta. This research used research method developed by Stufflebeam, that was CIPP model (Context, Input, Process, Product). The population in this study was all vocational students in Surakarta. The sample was 217 students with purposive sampling technique in 4 places namely SMK Negeri 2 Surakarta, SMK Negeri 5 Surakarta, SMK Pancasila Surakarta, and SMK Purnama Surakarta. The data was collected using interviews, observation, documentary studies and questionnaires. Data analysis for qualitative data used interactive analysis model and the quantitative data used assessment criteria. The results showed that, Context: (1) There is no official who joined OHS (2) The absence of detailed division of tasks. Input: (1) There is no system integrated with the school structure, (2) No officers are trained in OHS field, (3) OHS facility has standards with a percentage equal to 68,2\%. Process: (1) The use of OHS infrastructure belongs to high category with the percentage of $59,9 \%$. (2) Student motivation and awareness of OHS belong to high category with a percentage of $68,2 \%$. (3) OHS materials have been processed in basic subjects, only less training. Product: The implementation of OHS in School workshop belongs to high category with percentage of $82,5 \%$.
\end{abstract}

Keywords-OHS, vocational school, workshop, CIPP

\section{INTRODUCTION}

The development of industry in Indonesia takes place very rapidly along with the progress of science and technology in the era of industry 4.0 today. The process of industrialization of Indonesian society is accelerating with the establishment of diverse companies and workplaces. This rapid development is also accompanied by the presence of greater and diverse risk of danger due to the transfer of technology in which the use of machines and work equipment are increasingly complex to support the running of the production process.

The progress of industrialization, mechanization, and modernization, in most cases, increased the intensity of operational work and worker's tempo. This increase requires intensive deployment of workers as well. Consequently, workers experience fatigue and lack of attention which eventually lead to accidents while working.

Work accidents in 2011 occurred 96,400 accidents. As many as 96,400 workplace accidents happened, 2,144 workers were recorded dead, and 42 others were disabled, while until September 2012 the number of work accident was still high which was in the range of 80,000 cases. Occupational accident cases, in average, are 99,000 cases per year, and $70 \%$ of them resulted in death and disability. In 2013, it was recorded nine people die every day due to accidents. By the end of 2017, there were 80,393 cases.

The cause of accidents, in general, is due to the conditions and unsafe actions of workers. Specifically about the act of insecurity is closely related to the human factor or occurs due to human error. Another problem is that workers often do not want to use Personal Protective Equipment (PPE) that has been provided for various reasons. Also, there are workers who are less understanding about OHS [1]. Most supervisors did not receive information from the schools as to what should be included when introducing OHS at workplace [2].

The majority of industrial workers in Indonesia are middle-level workers. Vocational High School (SMK) is an educational institution that produces manpower/technicians at mid-level. The role of SMK is directly proportional to the industry's need for the large number of mid-level workers. This role encourages the advancement of vocational education institutions. By the National Development Plan of the Long-term Development Plan (RPJP) of the National Education year, 2005-2025 has been projected gradual and sustainable growth target of SMK leading to the increasing number of SMK compared to SMA will reach the ratio of $70: 30$ in 2025

SMK which is a container of labor producers is required to compromise the industry needs. The mastery of skills and knowledge of occupational health and safety includes those that are important to be mastered in supporting the production process in the industry. Occupational health and safety is the duty of everyone working in the workshop. Schools, in this case, become the key to understanding and mastery of occupational health and safety. Therefore, in vocational schools, especially practical learning should need to implement health and safety as in the workplace/industry 
environment. The importance of OHS and risk education is enhanced due to rapid development of the society, new technologies, and demographic changes [3].

Based on the above description, a study on the evaluation of health and safety workshop in Vocational High School in the city of Surakarta was conducted.

The questions in this study based on CIPP model background and concept evaluation (Context, Input, Process, Product) described as: (1). Context: Are there any Health and Safety commitments and policies in Vocational High School workshop in Surakarta? (2). Input: What is the guarantee of Occupational Health and Safety at Vocational High School Workshop in Surakarta? (3). Process: How is the implementation of Health and Safety at the Vocational High School workshop in Surakarta? (4). Product: How are the results of the implementation of Health and safety workshop in Vocational High School in the city of Surakarta?

\section{METHOD}

This research is an evaluation of CIPP model. This study used a population of vocational high schools in the city of Surakarta with a sample of 4 schools namely SMK N 2 Surakarta, SMK N 5 Surakarta, SMK Pancasila Surakarta, SMK Purnama Surakarta and 217 students of class XI and XII. The sampling technique used is purposive sampling. The following describes the instrument used in this study.

The sources of data used in this study include informants or resource persons, namely head of skill program, head of the workshop and productive teacher; respondents consist of the students of class XI and XII; places and events consist of facilities and activities in the workshop; Research instrument in the form of Questionnaire.

The validity of this research questionnaire instrument refers to the formula Product Moment correlation with a significance level of 5\%. The researcher used Pearson excel to determine the validity of each questionnaire statement, while the reliability of the instrument used the Cronbach Alpha formula.

Based on the test table validity of input variables can be seen from 20 items statement, there are 18 valid statements and two invalids. Grains declared valid direct the researcher to use them for data collection in research. Based on the test table validity of process variables, it can be seen in the table that of 34 items statement, there are 27 items valid statements and seven invalids. The grain of the declared valid statement directs the researcher to use them to collect the research data, while the invalid items were deleted since the other items have represented sub-indicator which has been predetermined. While the value of the instrument reliability obtained value Alpha of 0.993 . The value is greater than the required value of 0.6 which means the research questionnaire is reliable.

Data analysis in this study used two analytical techniques, namely descriptive data analysis and analytical data analysis. Descriptive data analysis used interactive model analysis technique [4].
TABLE I.

The TeCHNIQUe For COLLECTING DATA

\begin{tabular}{|c|c|c|c|}
\hline $\begin{array}{l}\text { Ev. } \\
\text { Aspect }\end{array}$ & Indicator & Data Source & $\begin{array}{l}\text { Research } \\
\text { Instrument }\end{array}$ \\
\hline Context & $\begin{array}{l}\text { 1. OHS Commitment and } \\
\text { Policy in the School } \\
\text { Workshop, including: } \\
\text { 2. OHS Organization } \\
\text { 3. Vision and Mission of } \\
\text { OHS Management } \\
\text { 4. Occupational Health } \\
\text { and Safety Management } \\
\text { Program } \\
\text { 5. Identify Existing } \\
\text { Conditions and Source } \\
\text { of Hazards }\end{array}$ & $\begin{array}{l}\text { Documents, } \\
\text { Archives, and } \\
\text { Informants }\end{array}$ & $\begin{array}{l}\text { Document } \\
\text { and Interview } \\
\text { Study }\end{array}$ \\
\hline Input & $\begin{array}{l}\text { 1. The availability of } \\
\text { Trained Personnel } \\
\text { (Competency OHS } \\
\text { Teacher) } \\
\text { 2. The availability of } \\
\text { Integrated Systems and } \\
\text { Procedures to the Board } \\
\text { 3. The availability of } \\
\text { Facilities, Pre- } \\
\text { Supporting Facilities } \\
\text { and the Environment }\end{array}$ & $\begin{array}{l}\text { Documents, } \\
\text { Archives, } \\
\text { Informants, } \\
\text { and } \\
\text { Respondents }\end{array}$ & $\begin{array}{l}\text { Document } \\
\text { and Interview } \\
\text { Study, } \\
\text { questionnaire }\end{array}$ \\
\hline Process & $\begin{array}{l}\text { 1. The use of Facilities } \\
\text { and Infrastructure } \\
\text { 2. Motivation and } \\
\text { Awareness of Teachers } \\
\text { and Students towards } \\
\text { OHS } \\
\text { 3. Training and OHS } \\
\text { Competency for } \\
\text { Teachers and students }\end{array}$ & $\begin{array}{l}\text { Documents, } \\
\text { Archives, } \\
\text { Informants, } \\
\text { and } \\
\text { Respondents }\end{array}$ & $\begin{array}{l}\text { Document } \\
\text { and Interview } \\
\text { Study, } \\
\text { questionnaire }\end{array}$ \\
\hline Product & $\begin{array}{l}\text { 4he existence of OHS } \\
\text { Systems Involving } \\
\text { Management, Teachers, } \\
\text { and Students to Reduce } \\
\text { the Occurrence of Work } \\
\text { Accidents in the School } \\
\text { Workshop }\end{array}$ & $\begin{array}{l}\text { Documents, } \\
\text { Archives, and } \\
\text { Informants }\end{array}$ & $\begin{array}{l}\text { Document } \\
\text { and Interview } \\
\text { Study }\end{array}$ \\
\hline
\end{tabular}

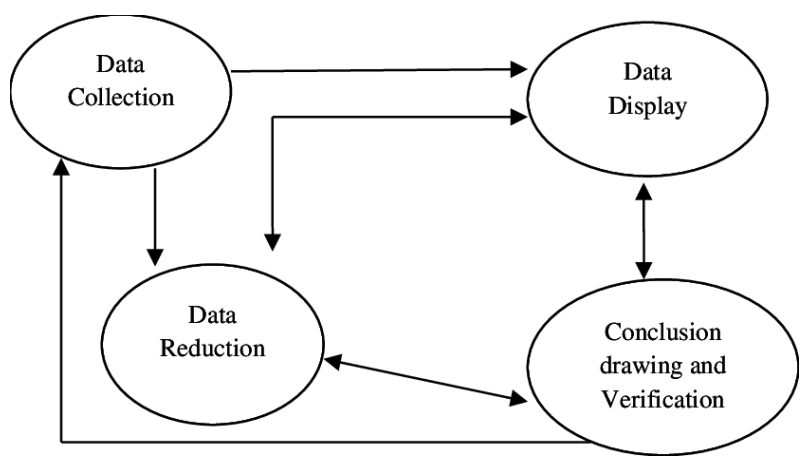

Fig. 1. Interactive model analysis

The analysis of the data is described as follows:

1) Data collection: Data collection is done by the procedure described previously, that is by interview, observation, and documentation. Data collection is continuously being done as long as the data obtained has not been fulfilled for the next process until the data obtained is sufficient. 
of health and safety in the automotive workshop has been done. However, there was no detailed and clear job description about health and safety of the workshop structure.

process of selecting, abstracting, and transforming coar data arising from records written in the field. This process is done by selecting the data that can be processed further to be arranged into a data dish. Data reduction is done to facilitate the researchers in conclusion and conducted during the study.

3) Data Display: Data display is the process of arranging data systematically, making it easier for researchers in concluding the results obtained in the field. Miles and Huberman define "Presentation of data as a set of arranged information, which provides the possibility of conclusions and taking action."

4) Conclusion: Based on data collection, data reduction, and data presentation, researchers can do a temporary conclusion. If there is new data/information affecting the validity of the current faults and conclusions, the temporary conclusions may be changed according to the results of the new analysis.

Analytical analysis of this study used the component assessment criteria developed by Saifuddin [5].

TABLE II. THE COMPONENT OF ASSESSMENT CRITERIA

\begin{tabular}{|l|l|}
\hline Score Range & Category \\
\hline$X \leq \mu-1,5 \sigma$ & Very low \\
\hline$\mu-1,5 \sigma<X \leq \mu-1,5 \sigma$ & Low \\
\hline$\mu-1,5 \sigma<X \leq \mu+1,5 \sigma$ & Medium \\
\hline$\mu+1,5 \sigma<X \leq \mu+1,5 \sigma$ & High \\
\hline$\mu+1,5 \sigma<X$ & Very high \\
\hline
\end{tabular}

Information :

$\mu=$ The ideal instrument that the instrument can achieve $=1 / 2$ (highest score + lowest score)

$\sigma=$ The ideal standard deviation that the instrument can achieve $=1 / 6$ (highest score - lowest score)

$\mathrm{X}=$ achieved score

\section{RESULTS AND DISCUSSION}

\section{A. Context}

The results of interviews on work health and safety commitments and policies in the school workshop were conducted with the head of the program, the head of the workshop and the practical teachers in each school to strengthen and confirm the findings of the document observation. From the data, it can be described that each school has not implemented the form of management in the implementation of OHS in the school workshop. Special organizations or personnel that regulate and supervise the course of occupational health and safety in school workshops have not yet exist. Duties and responsibilities so far have been included in the role of teachers and practitioners supervised by the head of the workshop. Structured arrangement regarding OHS applied in school workshop has not yet exist. Planning and evaluation of the implementation have not been running, if any, there was no clear job description since it has been included into the task of each teacher in the implementation of practical learning. From the findings that have been described, the actual implementation

\section{B. Input}

1) The availability of Integrated Systems and Procedures to School Management: From the interviews, it was found the conditions where schools, workshops, and teachers realized the importance of integrated system. However, if the system is run, it means that there should be an addition or procurement of things that support the realization of the system implementation, e.g., the presence of competent personnel in the field of OHS. If it is held, there must also be an improvement on its administration. Many things to consider according to the situation and condition of each school. Moreover, each school also has limited personnel. But in reality, there is no school that integrates OHS management with schools.

2) The availability of Trained Personnel: From the data obtained, it can be explained that in each school there is no trained personnel on health and safety. There is even no teacher data ever attending training on OHS. Each teacher can apply safety based on standard operational procedure (SOP) as a teacher. Each teacher, before carrying out teaching and learning activities, always prepare a lesson plan (RPP). In RPP practice activities, it is always inserted health and safety procedures. Work safety procedures are always used by teachers as a basis when running practice activities in the workshop.

3) The availability of Supporting Infrastructure: Data indicator of the availability of supporting facilities is also obtained from the questionnaire. Questionnaires are used to determine the availability of supporting infrastructure data from the opinions of respondents that have been prepared in a questionnaire. The supporting facilities included in the questionnaire are: 1) First Aid Kit, 2) Laundry, 3) Toilet/Bathroom, 4) Cleaner, 5) Sawdust, 6) Manual Book, 7) Waste Disposal Site, 8 ) OHS Rules, 9) Jobsheet, 10) Specialty Places for Practice Tools, 11) Ventilation.

The result of a questionnaire regarding the infrastructure can be seen in the following table.

TABLE III. AVAILABILITY OF OHS INFRASTRUCTURE

\begin{tabular}{|l|c|c|}
\hline Category & Frequency & Percentage \\
\hline Very high & 148 & $68,2 \%$ \\
\hline High & 69 & $31,8 \%$ \\
\hline Medium & 0 & $0 \%$ \\
\hline Low & 0 & $0 \%$ \\
\hline Very low & 0 & $0 \%$ \\
\hline
\end{tabular}

Based on the above table, it can be seen that the indicator of infrastructure facilities of each school is in a very high category with a percentage of $68.2 \%$. This indicates that the indicator of infrastructure facilities falls into the very high category. To facilitate in understanding the description of infrastructure indicators, the data is presented in the bar chart below: 


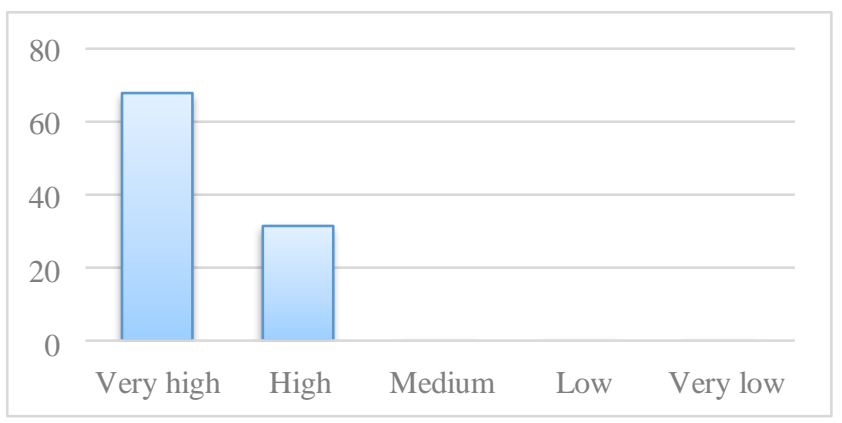

Fig. 2. The availability of Supporting Infrastructure Indicator

\section{Process}

a) The use of Infrastructure: The interview on indicators of infrastructure facilities use was conducted to the head of the program, head of the workshop, and teacher. The results can be illustrated that so far the use of OHS tools has been done well. In the practice, students have been using Personal Protective Equipment (PPE) in the form of work uniform but not other APD such as mask and gloves. Besides that, there is manual of each engine which is used for practice to facilitate student in doing dismantling and reassembling. The findings data indicator of the use of infrastructure facilities was also obtained from the questionnaire. More details can be seen in the table below:

TABLE IV. THE USE OF OHS INFRASTRUCTURE

\begin{tabular}{|l|c|c|}
\hline Category & Frequency & Percentage \\
\hline Very high & 130 & $59,9 \%$ \\
\hline High & 87 & $40,1 \%$ \\
\hline Medium & 0 & $0 \%$ \\
\hline Low & 0 & $0 \%$ \\
\hline Very low & 0 & $0 \%$ \\
\hline
\end{tabular}

The indicator of the use of infrastructure facilities in the category is very high with a percentage of $59.9 \%$. The table above can be clarified with the following bar chart picture.

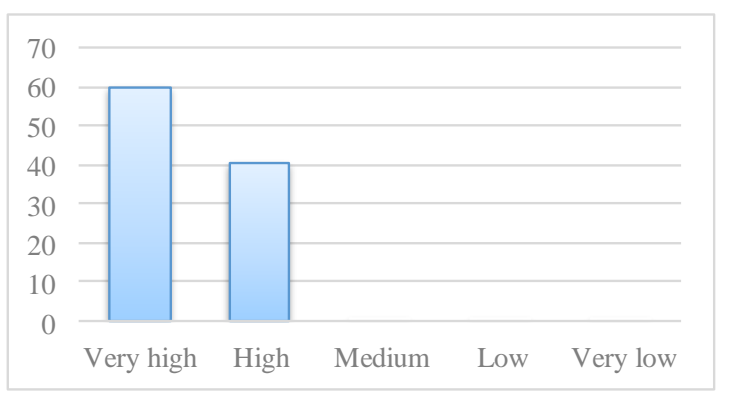

Fig. 3. The graph from the use of OHS infrastructure

b) Student's Motivation and Awareness of OHS: The results of the interviews conducted to the head of the program, the head of the workshop and the teachers of practice in each school indicated that students' awareness of OHS in the workshop is said to be $80 \%$. These findings are presented by informants (students) that in the practice, some students are not serious, more joking which can potentially cause accidents, such as playing with oil or fat also play with tools of practice. Teacher practitioners cultivate students' awareness in some ways including 1) briefing at the beginning of practice, 2) giving sanctions when some are not serious in practice, 3) showing videos about work accidents, so students are afraid not to be serious when practice.

The data on this indicator other than through interviews also obtained from the questionnaire. The results of categorization of the questionnaire can be seen in the table below:

TABLE V. STUDENT's MOTIVATION AND AWARENESS OF OHS

\begin{tabular}{|l|c|c|}
\hline Category & Frequency & Percentage \\
\hline Very high & 148 & $68,2 \%$ \\
\hline High & 67 & $30,8 \%$ \\
\hline Medium & 0 & $0 \%$ \\
\hline Low & 2 & $1 \%$ \\
\hline Very low & 0 & $0 \%$ \\
\hline
\end{tabular}

The indicators of student's motivation and awareness of OHS fall into a very high category with the acquisition of percentage equal to $68,2 \%$. The data on student motivation and awareness indicators on OHS are shown in the following bar charts:

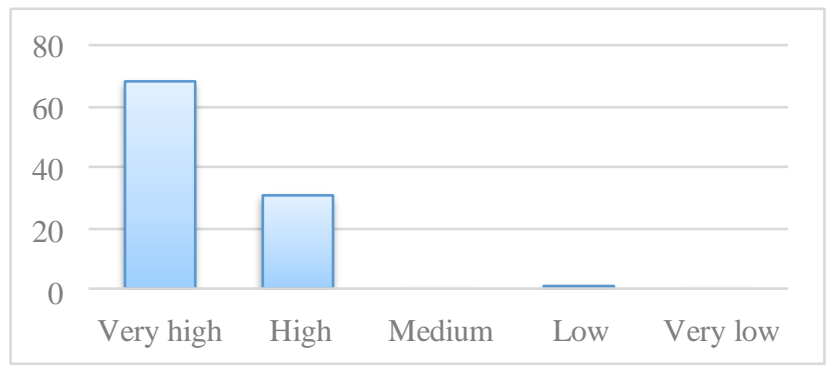

Fig. 4. The graph from student's motivation and awareness

c) OHS Competencies of Teachers and students: The Interview data results: 1) competence of OHS mastery for students by way of inclusion to the basic subjects in class X. In basic learning, OHS only delivered a theory containing the introduction and how the prevention of work accident. In practical learning, teachers always provide guidance in the beginning before the practice begins. As for OHS training, in each school, there was no training conducted related to health and safety. At SMK 5 Surakarta and SMK Pancasila Surakarta had once conducted firefighting training in collaboration with the fire department but was only followed by students who have been appointed previously.

The data above shows that in each school has never been conducted any training on health and safety for teachers and practitioners of students, but for students of OHS competence have been included in basic lessons of vocational techniques.

This is inversely related to the theory review that OHS training is necessary to ensure safety [6]. The 'professional knowledge of reference' needs to be identified to design training content that combines the 'regulated safety' and 'managed safety' necessary to produce safe working conditions. The objective of education in the field of OSH is to equip students with the necessary knowledge, information and develop their abilities and skills [7]. The one way attempt 
to minimize the number of occupational accidents is through education and training [8].

For the efficiency and effectiveness of OHS training, there is no need to provide high-cost face-to-face meetings, but can use online tutorials [9].

\section{Product}

The data shows that there have been no serious workplace accidents in the workshops of each school, while accidents have occurred only minor accidents that can be handled immediately and do not result in serious injuries or impacts to students. During this implementation of safety, each school has involved all teachers, especially teachers practice assisted by students. But there has not been a system with written regulation about health and safety at the workshop. So far, the only form is in informal consensus. The results of direct observation in the field using the checklist obtained results with a percentage of $82.5 \%$, or it can be said that the implementation has been running well and been to in high category. This checklist sheet is based on labor minister's regulation no. PER.05/MEN/1996 on health and safety management system.

Based on CIPP evaluation, it is important to note about OHS management and its training for safe work safety. Vocational School that OSH-based is one way to prepare students to enter work [10]. Also, the future strategic direction of OHS as a provision of occupational health services for safety and health of students and workers guaranteed [11].

\section{CONCLUSION}

Each school has not implemented a OHS system correctly. Special organizations or personnel dealing with occupational health and safety in the workshop do not yet exist. The supervisory and regulatory tasks are carried out by the program chair, while direct supervision and responsibility when the student's practice has been included become the task of the practice teachers. Job description in detail regulating the implementation of health and safety in the workshop does not exist yet.

Work accident management systems and procedures do not yet exist in each school. During this accident handling is still handled by the workshop, after handling the workshop, there is a report to the principal through the deputy head of the school to take care of student insurance in case of serious accident. Teachers in each school have never attended training or competency training in the field of occupational health and safety at workshops. The infrastructure available in each school meets the requirements outlined in the regulation of the national education minister, although for the size of each state has not been suitable due to limited land and also in the refinement process. The infrastructure facilities in each school in the category are very high with the acquisition percentage of $68,2 \%$. The infrastructure facilities from the observations also showed high category with the percentage acquisition of $80.6 \%$.

The maximum use of facilities by students is in a very high category with a percentage of $59.9 \%$. Based on these results, it is indicated that the students have used the existing infrastructure in the workshop according to the procedure and its usefulness. Students have utilized the existing infrastructure in the workshop when practicing.

Motivation and awareness of students on health and safety in the category are very high with a percentage of $68.2 \%$. Based on these results, it shows that students have been aware of the importance of health and safety practices when practicing in the workshop. Health and safety competencies for students have been incorporated into elementary learning when in grade X. Training for teachers on occupational health and safety has never been held. The training for teachers is usually held by the department, while the school has not conducted any training on OSH.

The planning, implementation, and evaluation of OHS in the workshops in each school is undocumented, as long as it is only done orally. Establishing a system in the application of occupational health and safety at workshops involving management, teachers, and students that materialize with no accident occurring in the school workshop. Implementation of OHS in the workshop has a high percentage of $82.5 \%$ which can be said during this implementation of OHS in the workshop has been running well.

\section{ACKNOWLEDGEMENT}

The acknowledgement was submitted to the education and sports department of Surakarta that has permitted to obtain data in vocational schools located in the area of Surakarta.

\section{REFERENCES}

[1] Andersson, I. M., Gunnarsson, K., Rosèn, G., \& Moström Åberg, M.,"Knowledge and experiences of risks among pupils in vocational education," Safety and Health at Work, vol. 5(3), pp. 140-146, 2014

[2] Andersson, I. M., Gunnarsson, K., \& Rosèn, G., "Role of headmasters, teachers, and supervisors in knowledge transfer about occupational health and safety to pupils in vocational education," Safety and Health at Work, vol. 6(4), pp. 317-323, 2015

[3] Reinhold, K., Siirak, V., \& Tint, P., "The development of Higher Education in Occupational Health and Safety in Estonia and Selected EU Countries," Procedia - Social and Behavioral Sciences, vol. 143, pp. 52-56, 2014.

[4] Miles, M. B. \& Huberman, M, Analisis Data Kualitatif. Jakarta: Penerbit Universitas Indonesia, 1992.

[5] Anwar, Saifuddin, Metode Penelitian. Yogyakarta: Pustaka Pelajar, 2010.

[6] Vidal-Gomel, C., "Training to safety rules use. Some reflections on a case study," Safety Science, vol. 93, pp. 134-142, 2017.

[7] Feszterová, M., "Education for Future Teachers to OHS Principles Safety in Chemical Laboratory," Procedia - Social and Behavioral Sciences, vol. 191, pp. 890-895, 2015.

[8] Endroyo, B., Yuwono, B. E., Mardapi, D., \& Soenarto, "Model of learning/training of Occupational Safety \& Health (OSH) based on industry in the construction industry," Procedia Engineering, vol. 125, pp. 83-88, 2015

[9] Van Dijk, F. J., Bubas, M., \& Smits, P. B., "Evaluation Studies on Education in Occupational Safety and Health: Inspiration for Developing Economies," Annals of Global Health, vol. 81(4), pp. 548-560, 2015.

[10] Pisaniello, D. L., Stewart, S. K., Jahan, N., Pisaniello, S. L., Winefield, H., \& Braunack-Mayer, A., "The role of high schools in introductory occupational safety education - Teacher perspectives on effectiveness, " Safety Science, vol. 55, pp. 53-61, 2013.

[11] Harrison, J., \& Dawson, L., "Occupational Health: Meeting the Challenges of the Next 20 Years," Safety and Health at Work, vol. 7(2), pp. 143-149, 2016. 